\title{
GAME PLAYING AND OPERATIONS MANAGEMENT EDUCATION
}

\author{
Michael A. Lewis and Harvey R. Maylor \\ Operations and Supply Group, University of Bath School of Management, Bath, UK.
}

There is a well established tradition of teaching operations management (OM) via various kinds of production game: real players making real decisions in a practical, albeit simulated, situation. Surprisingly, there has been much less conceptual reflection on the process and content of this approach to OM education, something this paper aims to begin to rectify. The first section clarifies terminology and defines the game concept in terms of a transformation process. The second section reviews the extant population of teaching games and deploys the conceptual model to generate a number of specific observations that underpin a discussion about the content and process of OMrelated game playing. In the conclusions, particular attention is drawn to (1) the predominant content of OM-related games has not developed with the same emphasis as the taught subject with manufacturing planning and control still dominating (2) the tendency to produce complex OM games requiring IT support, and (3) the removal of competition in gaming in favour of facilitating experimentation by players. The paper finishes with a discussion of potential further work.

Keywords: Games, playing, teaching, competition, experimentation

Address for correspondence:

Dr. Harvey Maylor, School of Management, University of Bath,

BATH.

BA2 7AY.

UK.

Email: h.maylor@bath.ac.uk 


\section{Introduction}

Operations Management (OM) education employs a wide variety of games (Riis and Mikkelsen 1995), ranging from simple 'tabletop' (Robinson and Robinson 1994) and 'red bead' experiments (Deming 1986), to system simulations like the Beer (Forrester 1961, Senge 1990) and Cuppa Manufacturing games (Ammar and Wright 1999), to much more complex interactive environments such as a 'training factory' (Haapsato and Hyvönen, 2001). This interest in 'playing' can be explained in a number of ways. Games and simulations address specific OM concerns that the "...interesting and challenging issues ... are difficult to convey effectively in a purely theoretical setting [because] students need some way to directly experience the issues involved in operating a production system" (Ammar and Wright 1999, p. 183). This can be particularly important when the taught course represents a students' first exposure to operations management practice but experienced students can also find their own knowledge a barrier to new concepts. More generally therefore, gaming promotes 'experiential learning' by providing a shared 'concrete experience' (Kolb, 1985) that many argue allows the student to explore theory and practice more critically and (hopefully) memorably (McKenney 1962; 1967, McKenney and Dill 1962; Haapasalo and Hyvönen 2001). Additionally, some authors (e.g. Smeds 1997) have argued that there is potential to use gaming as a form of 'co-production' of knowledge that might overcome traditional barriers to academic-practitioner knowledge transfer.

This paper was motivated in large part by the authors' practical experiences of game playing in an educational context. Both felt that they had developed 'experiential' insight into a range of specific games but lacked (1) a conceptual schema for understanding the educational process involved and (2) a comprehensive guide to both the educational content and playing process of OM-specific games. The paper begins by discussing the general historical and conceptual antecedents of teaching with 'organisation-themed' games. Concepts are extracted from existing definitions of games and a generic transformation model of game playing in $\mathrm{OM}$ is proposed. Then using a range of secondary data, specifically a survey of $222 \mathrm{OM}$-specific and OM-related games derived from published gaming texts and references, two empirical research questions are tackled. Firstly, what is the content of OM games? This is an important question as the nature of $\mathrm{OM}$ has changed significantly in the recent past, and we need to establish whether the games' content has kept pace with this change. Secondly, what is the process for the games? Specifically, how long do they take, how many people are involved and what is the level of complexity and the physical requirements? The paper concludes with recommendations for further work. 


\section{Conceptual Background}

To think about playing a game is, for most people, to consider engaging in a diverting (i.e. not serious) mental and/or physical activity that might involve other people. At the same time, other participants can treat exactly the same set of activities very seriously indeed. Players of even the most apparently trivial games can be 'professional' and some earn huge salaries from participating. Moreover, the economics of these earnings are dependent upon large numbers of people (i.e. spectators, fans, etc.) deriving pleasure from simply watching their game play. In addition to various forms of entertainment, games are used in teaching (from primary to post-graduate level), training, therapy/diagnosis and experimentation (Shubik 1975a). There are also many pejorative connotations to games - many managers for instance, will assert that they have to 'play the game' if they want to get on in their organisation (Weir 1997). In other words, although games and game playing are deeply ingrained in human nature (Homo Ludens: Huizinga 1971), they remain complex and ambiguous phenomena.

\subsection{The Development of Educational Game Playing}

Although the precise origins of games designed to represent and thereby 'educate' players in aspects of organisational life are difficult to establish, three specific historical developments are worth highlighting.

First, most early writers on business gaming drew heavily on the notions of competitive conflict implicit in military and political games (e.g. Shubik 1975b, Bowen 1978). The history of military gaming is particularly important, including chess-type games in prehistoric India, kriegspiel (German: krieg - war; spiel - game) in $19^{\text {th }}$ century Prussia and modern US IT-integrated war planning (Shubik 1975a, 1975b, Allen 1987). Similarly, in the years following WWII a number of defence-related institutes (e.g. RAND Corporation) developed a range of strategic and operational 'games' based upon principles of operational research and game theory. How and whether these should be counted as 'games' is discussed in the next section.

Second, the proliferation of management (Gordon and Howell 1959) and industrial engineering courses (Emerson and Naehring 1984) created a context where games could create educational market value (e.g. "...with the increasing general recognition of the importance of the management profession has come insistence on better and shorter methods of acquiring management experience - at least 
vicariously": Graham and Gray 1969, p.17). This pressure on staff and timetables has not in any sense decreased in the intervening years. In an early example (1956) of a business game, the American Management Association created the "Top Management Decision Simulation". Within ten years a survey revealed that two-thirds of US business schools had adopted related gaming techniques (Klasson 1964).

Finally, the widespread adoption of gaming approaches was enabled by the emergence of affordable (micro-) computing power - albeit in the first instance affordable only to the large corporation and/or university. Today, ever greater processing power and network interactivity at lower cost has meant that complex simulation is now possible using ordinary desktop PCs. As a result many games, especially those "focus[ed] on a single, specialized phenomenon" (Elgood 1997, pp.12) are heavily IT-dependent.

In addition, given this broad and extended heritage, it is unsurprising to discover "that different traditions... have their own [gaming-related] terminology and specific connotations are attached to it. Definitions therefore remain a significant problem, and users of management games sometimes appear to be talking at cross purposes." (Elgood 1997, p.11). Definitional issues are therefore clearly of importance and Table 1 presents a chronological series of competing definitions. Despite all the points of divergence and the confusing overlaps between definitions (games, simulations, simulation games, etc.) it is still possible to identify a number of common themes that can form a usefully generic conceptualisation of gaming and help in the consideration of the process of gaming. 


\begin{tabular}{|c|c|c|}
\hline TERM & DEFINITION & NOTES \\
\hline $\begin{array}{l}\text { Business } \\
\text { Game }\end{array}$ & $\begin{array}{l}\text { "...simplified abstractions of a situation related to the } \\
\text { business world. The game participants, either } \\
\text { individually or in groups, manage a whole firm or an } \\
\text { aspect of it, by making business decisions for } \\
\text { successive periods (Acer 1960, p.7: in Carson 1967) }\end{array}$ & $\begin{array}{l}\text { An emphasis on the use of "mathematical } \\
\text { abstractions" that are then used to create case studies } \\
\text { that generate feedback over time. }\end{array}$ \\
\hline $\begin{array}{l}\text { Business } \\
\text { Simulation } \\
\text { or Game }\end{array}$ & $\begin{array}{l}\text { "...a sequential decision-making exercise structured } \\
\text { around a model of a business operation, in which } \\
\text { participants assume the role of managing the } \\
\text { simulated operation" (Greenlaw et. al 1962, p.5) }\end{array}$ & $\begin{array}{l}\text { Two types of game: "general management games to } \\
\text { teach decision-making at top management level" and } \\
\text { "functional games intended to teach specific skills...or } \\
\text { value of specific...decision rules such as the EOQ." }\end{array}$ \\
\hline $\begin{array}{l}\text { Business } \\
\text { Game }\end{array}$ & $\begin{array}{l}\text { "...extension of case study methods of teaching. } \\
\text { Participants (players)...normally make a sequence of } \\
\text { decisions where changing....factors must be } \\
\text { considered. Participants project themselves into the } \\
\text { game rather than study a [static] case as an outsider" } \\
\text { (Babb and Eisgruber 1966, pp.15-17). }\end{array}$ & $\begin{array}{l}\text { Games are "related to simulation ...models } \\
\text { of...essential characteristics of real world situations". } \\
\text { "It is unfortunate that this term [game] conveys the } \\
\text { impression that the primary purpose...is entertainment } \\
\text { rather than a serious and valuable approach to } \\
\text { teaching (and research)..." (pp.15-16). }\end{array}$ \\
\hline Game & $\begin{array}{l}\text { "...competitive mental activity wherein opponents } \\
\text { compete through the development and } \\
\text { implementation of an economic strategy" (McKenney } \\
\text { 1967, p.2). }\end{array}$ & $\begin{array}{l}\text { "Gaming is a pragmatic and nondirective approach... } \\
\text { [T]he designer must develop...problems such...that } \\
\text { they will be challenging...over an extended period } \\
\text { without [being] overwhelming....at the start." (p.2) }\end{array}$ \\
\hline $\begin{array}{l}\text { Simulation } \\
\text { Game }\end{array}$ & $\begin{array}{l}\text { Comprises the: model, "an abstraction of an economic } \\
\text { environment"; simulation, "the series of rules for } \\
\text { manipulation of the model"; game, "a set of rules } \\
\text { which govern the activity of the participants in relation } \\
\text { to the simulation" (McKenney 1967, p.2). }\end{array}$ & $\begin{array}{l}\text { The simulation rules [e.g. "select the minimum of } \\
\text { inventoried material, allocated labour and prior plant } \\
\text { capacity as the production output for the decision } \\
\text { period", (p.3)] are generally programmed for a } \\
\text { computer. }\end{array}$ \\
\hline Game & $\begin{array}{l}\text { "A paradigm for competitive and/or co-operative } \\
\text { behaviour within a structure of rules. The rules vary in } \\
\text { formality in free form or rigid-rule gaming...But all } \\
\text { games call for an explicit consideration of the role of } \\
\text { the rules." (Shubik 1975a, p.45). }\end{array}$ & $\begin{array}{l}\text { "Gaming, in contrast to simulation, of necessity } \\
\text { employs human beings. A gaming exercise may } \\
\text { employ human beings acting as themselves or playing } \\
\text { simulated roles in an environment which is either } \\
\text { actual or simulated" ( }(\text {. .). }\end{array}$ \\
\hline Game & $\begin{array}{l}\text { "...people, individually or in groups, in a competitive } \\
\text { situation. They have resources they dispose of } \\
\text { according to rules, dealing with losses/gains...moves } \\
\text { may be simultaneous or sequential. They develop } \\
\text { strategies for winning and make and implement } \\
\text { decisions. [lt] need not, but often does, possess some } \\
\text { attributes of 'real' situation." (Bowen 1978, p.3). }\end{array}$ & $\begin{array}{l}\text { "...if game is to be of operational use, the purpose will } \\
\text { be to develop some understanding of the way in which } \\
\text { purposeful behaviour can affect the situations } \\
\text { occurring in the game.... [it] will model real situations } \\
\text { in which an individual wishes to make more informed } \\
\text { choices... [it] needs to have a model of the systems } \\
\text { involved and of the environment" (p.4). }\end{array}$ \\
\hline Simulation & $\begin{array}{l}\text { "[their] purpose is to help to understand and solve } \\
\text { complex real-life problems by constructing a small, } \\
\text { simplified version of the problem, often called a } \\
\text { 'model'... users have a set of goals, implicit or explicit, } \\
\text { which they seek to achieve, either in the short or long } \\
\text { term....Participants have to pursue these goals by } \\
\text { taking action or making a set of decisions." (Fripp } \\
\text { 1993, pp. 8-22) }\end{array}$ & $\begin{array}{l}\text { "In operational simulations [to show the performance } \\
\text { of people, plant or equipment under a variety of } \\
\text { different operating conditions] the decisions relate to } \\
\text { the acquisition and use of physical resources. In } \\
\text { behavioural simulations [to illustrate group behaviour] } \\
\text { some of the main decisions might be how participants } \\
\text { use their time and the amount and manner of } \\
\text { communications with others" (p.20). }\end{array}$ \\
\hline Game & $\begin{array}{l}\text { Activities with some/all following characteristics: } \\
\text { "human opponents, actions have an effect upon each } \\
\text { other and environment; emphasis on competitiveness } \\
\text { and 'winning'; emphasis on humour and enjoyment; } \\
\text { repetitive cycle of making decisions and encountering } \\
\text { result, allowing hope of improvement and 'doing better } \\
\text { next time'." (Elgood 1997, p.12). }\end{array}$ & $\begin{array}{l}\text { A business game (or simulation) is simply one having } \\
\text { an "industrial, commercial or financial background". A } \\
\text { management game (or simulation) is one concerned } \\
\text { with the planning, management and control of any } \\
\text { organization or project in circumstance where profit is } \\
\text { not the dominant measure of success." }\end{array}$ \\
\hline
\end{tabular}

Table 1. Defining Games, Business Games and Simulations (Chronological Order)

\section{As can be seen, there are some common themes emerging from the definitions above - notably that simulations and games appear to be different. Specifically, a}


simulation is a simplified, abstracted model with rules; a game is when people have the opportunity to 'play' within the environment of the simulation (Schrage, 1999).

From the above it appears that there are two non-exclusive elements of this play; the first is competitive, the second experimental. The first is an opportunity harness the dynamic of having other people trying to achieve the same thing. Such competition, we have observed to be almost always beneficial to the student experience, creating an additional pressure analogous to a competitive market. The second kind of play, is the experiment - giving the opportunity to see the effects of one or other strategy, but without having the benefit of a human competitor.

An element that comes through of the gaming process, is of "developing understanding of the process" (Bowen, 1978) "without being overwhelming," (McKenny, 1967). This shows that part of the process of gaming is a sensemaking one (Weick, 1995) and that this can usefully be guided by the tutor or umpire.

Moreover, it is clear that gaming is not simply a mental exercise (cf. McKenny, 1967). In OM games, particularly production scenarios, there are regularly artefacts that are changed by the gaming process. Process-based analysis is at the root of OM teaching, and includes the most basic of considerations - the transformation model. This is now applied to the gaming process.

\subsection{A Transformation Model of Game Playing}

Rather than propose yet another definition this paper argues that because there are factors common to all games, OM game playing can be usefully represented (see Figure 1 ) by a transformation (i.e. input $\rightarrow$ process $\rightarrow$ output) model. 


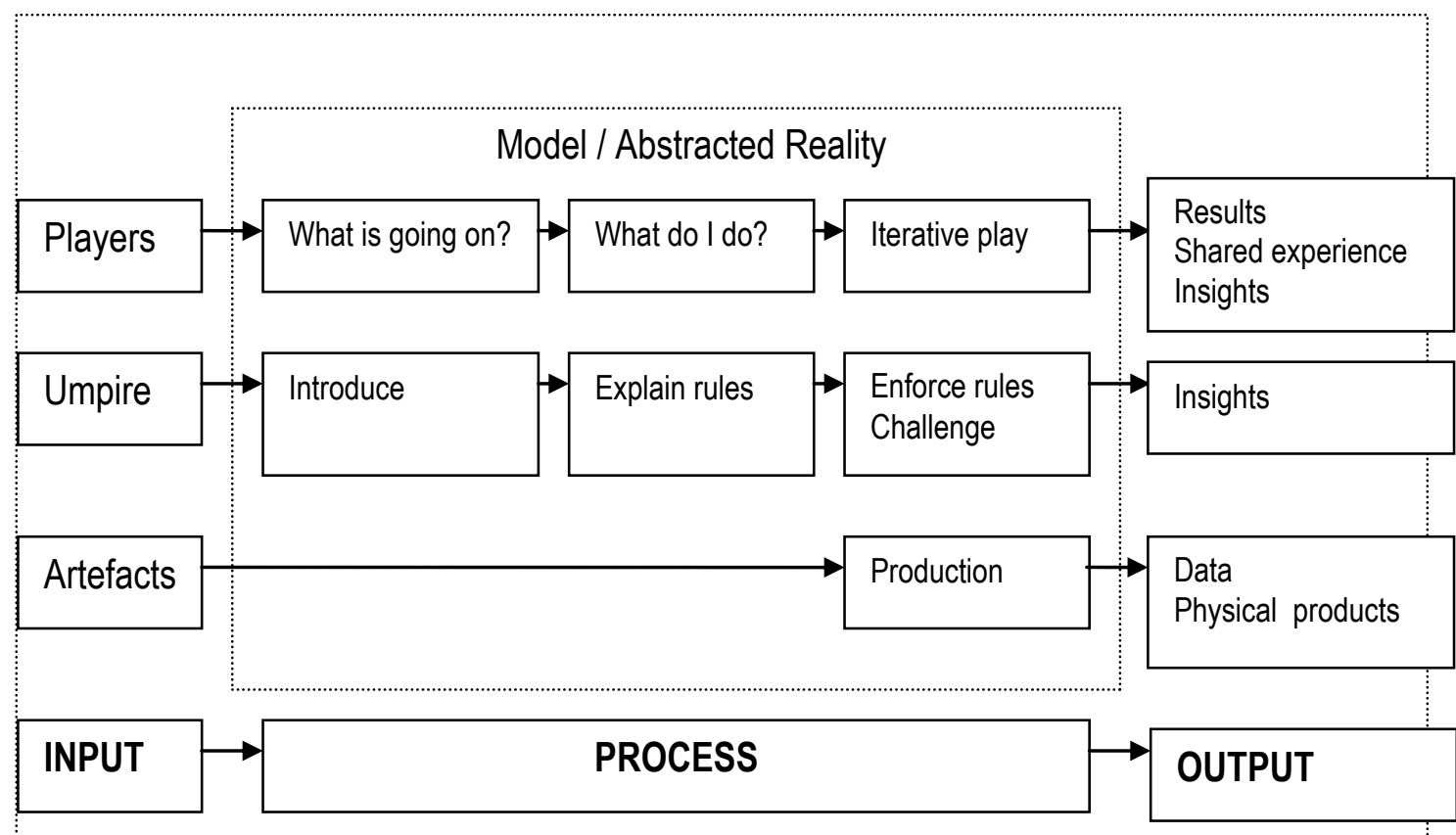

Figure 1. An 'Input $\rightarrow$ Process $\rightarrow$ Output' Model of OM Gaming

The generic model shows the three major inputs being the players, the umpire and the artefacts of the game, and the nature of the transformation process. Artefacts are the whole supporting infrastructure, including any IT support, physical resources and information provided to the player. The transformation is predominantly focused on the ideas of the players and umpire. During the process, basic sensemaking is identified through the first two stages that participants have to complete, and the decisions that they make before doing the physical activity of the game, if appropriate.

The model of the process is also useful in the analysis of the role of IT within an OM game, following the basic principle of operations that the process should be understood and simplified before being automated. A piece of software for instance, can potentially aid in the introduction and explanation of the game. Where a 'real' element of a game is used however, it may be inappropriate to be able to ensure that rules are upheld, but is excellent at calculating results, for instance.

In order to clarify the generic model, it is helpful to populate it with the characteristics of a specific OM-related teaching game: Cuppa Manufacturing ${ }^{1}$. This game is designed to illustrate the advantages and principles of Just-In-Time production systems over traditional batch and queue. The scenario is a model of a basic

\footnotetext{
${ }^{1}$ The precise origins of this JIT game are unclear. The authors first encountered the game being played by Professor Denis Severance of Michigan University but Ammar and Wright (1999) cite a Cornell University product development module (Jackson 1996) as the source.
} 
assembly process - abstracted and simplified and with rules established as to how the process needs to work.

\subsubsection{Inputs}

In the Cuppa Manufacturing game, players are allocated specific tasks detailed in the rules. One acts as a supplier, providing all raw materials to each of the four workstation players (in order: place cups in tray; stick dots to side of cups; place lids on cups; unwrap straws and insert into lids) and another acts as final quality control/shipping co-ordinator. Depending upon the size of the group, additional jobs can be allocated - such as production manager, time and motion consultant, customers, etc. The rules include a demand requirement and prescribe both the product assembly process and the initial configuration of the production system. In terms of artefacts, cups, lids, straws, red dots and trays, and stopwatches are made available so that players (and observers) can time different activities. Also, the game needs to take place in a large enough space to allow 3 or 4 large tables to be placed side-by-side.

\subsubsection{Process}

In common with many 'organisational' games, it is normal that players initially feel somewhat bemused and therefore the umpire needs to be very familiar with all of the tasks. This is to allow the first two stages of the gaming process to be accomplished as the players make sense of the environment. It is notable how different groups, even within a fairly homogeneous cohort, have radically different speeds in satisfactorily achieving this. In many games, the level of control exerted by the umpire is deliberately minimal - despite the game being based upon a complex set of rules - with the implicit purpose of allowing players to 'figure it out' for themselves and thereby explore their own (and/or colleague) behaviour in the light of specific scenarios. At the same time, in order to aid the 'teaching' of specific content (i.e. theories, hypotheses etc.), other games are carefully controlled so that 'events of interest' actually occur and corresponding principles can be demonstrated.

The second part of the gaming process comprises two basic components: the sequential or simultaneous decisions made and activities completed by the players and, the interventions made by the game umpires. Some planning is allowed off-line to allow the players to simulate the process themselves, before the actual timed production process starts. 
The Cuppa Manufacturing game is based upon the repetitive assembly of a tray of four 'fast food' cups complete with lids, straws and a red-coloured adhesive dot.

Figure 2 illustrates the basic cup sub-assembly.

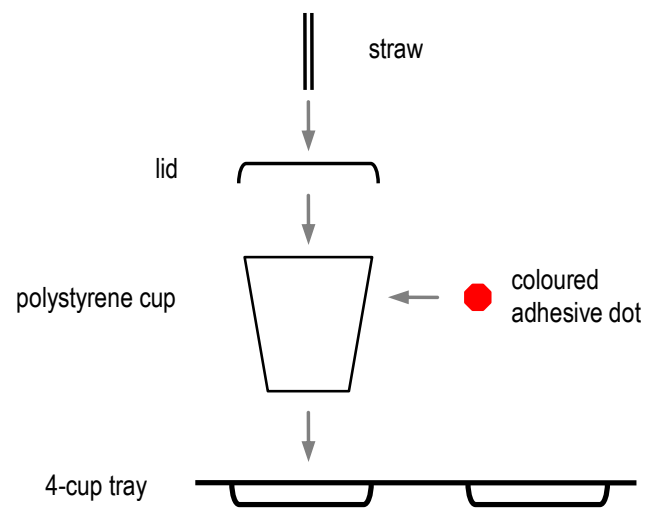

Figure 2. Single Unit Product (cup sub-assembly) for Cuppa Manufacturing Game (4 per tray)

'Iterative play' in this case is usually structured around three or four 'rounds' where participants are given the opportunity to 'improve' the production system. The first iteration replicates a classic batch (e.g. 4 trays per batch) push production system. Inventory quickly builds as imbalances in the line become clear, table space is used up and process control (e.g. consistent placing of coloured dots) becomes impossible. A tracer tray (e.g. with a coloured edge) can then introduced to obtain a throughput time. Additional quality problems can also be deliberately introduced: such as the replacement of red dots with blue ones, this change often goes unnoticed until final inspection (or the customers' goods inwards receipt). After 10-15 minutes of play, most of the problems with the system should be apparent and the game can be halted. The umpire then challenges the players to measure what is going on and try to analyse what is going wrong. Performance metrics used include: work-in-process, table space, throughput time, output efficiency, defect levels etc. The extent to which improvements carried forward into subsequent 'rounds' are entirely selected by the players (e.g. analysis often leads players to argue for additional workers and space at bottlenecks and/or for the introduction of additional quality control checks) or driven forward by the umpire (e.g. "next round we'll try a batch of 4 pull system") will depend upon the overall purpose of the game, the time available, the type of players etc. Typically, round two will involve a 'push four' system with better balancing, round three will move towards a 'pull four' system and round four will further reduce the batch size. The game does not require any IT support, and can be played in either competitive or non-competitive modes. 


\subsubsection{Outcomes}

A key component of any game will normally be some kind of measurable performance outcome - the results. This, allied with competitive dynamics, can be an important source of individual and group motivation and therefore any scoring system needs to be perceived as either intrinsically fair and/or reflective of a 'real world' outcome. Players of the Cuppa Manufacturing game can quickly see the impact of production imbalance, high levels of WIP and experiment with pull production solutions. Given that 'lean' production techniques can seem (at least initially) to be somewhat counter-intuitive, the discovery that smaller batch sizes, less space and fewer staff can actually create a more effective (i.e. faster) and efficient system is often hugely revelatory (Ammar and Wright describe (rather worryingly?) how "many become instant believers") - such a learning experience is clearly a significant outcome of the game. Equally, the game encourages the players to question and modify the system rules between iterations - such that fundamentally different production rules should be another outcome. Finally, and despite the apparent simplicity of the game, every play evolves slightly differently. The team dynamics will vary, initial changes can hinder subsequent, often more fundamental improvements (e.g. after initially adding more capacity at bottlenecks, it seems to be more difficult to reduce it quickly afterwards - players often articulate a "well, we've added that capacity/spent that money etc. so we may as well use it" logic) and specific interventions (e.g. changing dot colour) can be made. As a result, another outcome of each completed game play will be an increasingly experienced umpire(s) with quite often, useful insights into the behaviour of actual managers and systems.

The above discussion has taken a basic transformation model of a gaming process derived from prior definitional work on gaming, and populated the model using a specific example of a short production game, that is consistent in nature with the most popular games (e.g. beer game). It has shown the role of the different parties, the nature of the sensemaking process that is required, and given clues as to the parts of the process that could be automated (e.g. through use of IT support to replace human input) - though in this case, it is neither necessary nor inherently desirable.

\subsection{Research Questions}

This paper takes these themes forward by asking the research questions: 
1. What is the content of OM games? This is an important question as the nature of $\mathrm{OM}$ has changed significantly in the recent past, and we need to establish whether the games content has kept pace with this change.

2. What is the process for the games? Specifically, their duration, number of people involved and the level of complexity need to be analysed, along with the physical requirements.

Population of the model with a greater range of games in answering the research questions, starts in the following section.

\section{Research Methodology}

In order to investigate the key research questions, using as many OM teaching and training games as possible, empirical data is primarily drawn from a catalogue of 572 games derived from three key gaming and simulation publications.

(A) Graham and Gray (1969) surveyed Fortune 500 training and personnel managers and identified different business games ${ }^{2}$ developed since 1956.

(B) Elgood (1997) is currently in its $6^{\text {th }}$ edition - making it arguably the most popular and enduring gaming text - provides an alphabetical list of games/simulations ${ }^{3}$, categorising them according to 70 different disciplinary, functional, relationship and skill headings.

(C) Finally, a recent (2002) on-line catalogue of OM games (http://www.iprod.auc.dk/x-proj/gamespm/www-games.html), developed by a European Union funded research group ${ }^{4}$, is also included.

Such a secondary data approach has a number of specific advantages and limitations. The game catalogues provide teachers with summary information on games that are available to be disseminated, suggesting that any games included have been successfully applied on a number of occasions. The 222 (41.34\% of 572) games classified as OM-related provide a data set that is large enough to improve the external validity of any conclusions. Additionally, the sources provide a basis for

\footnotetext{
2 Graham and Gray (1967) describe each game using the following structure: (1) description; (2) training purpose; (3) decisions made by participants/administrator; (4) administration; (5) source.

${ }^{3}$ Elgood (1997) describes each game using the following structure: (1) principal use(s); (2) background; (3) type of game/simulation; (4) suitability; (5) acceptable numbers; (6) time requirement; (7) intellectual/behavioural balance; (8) what participants will be doing; (9) how the game/simulation works; (10) in game objectives of participants; (11) knowledge areas covered; (12) behavioural skills/qualities developed; (13) availability; (14) source.

${ }^{4}$ Created by a Special Interest Group of the IFIP Working Group 5.7 on Integrated Production Management, it was set up to stimulate the development and use of games for production management in education and industry. The group holds regular workshops: the proceedings of their $3^{\text {rd }}$ workshop, for instance, have been published (Smeds and Riis 1998).
} 
exploring the evolution of OM gaming over an extended timeframe. Problematically, each source adopts a different data collection method and the breadth of the data set means that there is less space for discussion of the detailed 'reality' of each game.

\begin{tabular}{|l|l|l|l|l|}
\hline SOURCE & NO. GAMES & OM GAMES & OM SPECIFIC & OM RELATED \\
\hline A. Graham and Gray (1969) & 183 & $84(45.9 \%)$ & 38 & 46 \\
\hline B. Elgood (1997) & 354 & $103(29.1 \%)$ & 40 & 63 \\
\hline C. IFIP $(2002)$ & 35 & $35(100 \%)$ & 35 & \\
\hline TOTAL & $\mathbf{5 7 2}$ & $\mathbf{2 2 2 ( 3 8 . 8 \% )}$ & 113 & 109 \\
\hline
\end{tabular}

Table 2. Summary of Key Game Data Set

Table 2 provides an overview of the OM-related games included in the study: 113 (50.9\%) are games concerned with the exploration/illustration of specific OM techniques/methods and 109 (49.1\%) are general/whole organisation games with significant operations/production management content.

\section{Discussion}

The number of games identified appears to confirm that there is a long and strong tradition of employing games in OM education (Riis 1995). Analysis of the data set is structured around the linear gaming model introduced earlier but unfortunately, although many of the game descriptions include some discussion of player type (practitioner, student, introductory, advanced, etc.), the game data only supports meaningful discussion of process and outcome issues.

\subsection{The Content of OM Games}

The proportion of OM games is not consistent between set $A(45.9 \%)$ and $B(29.1 \%)$. It is likely that this is explained by two factors: $B$, the later and larger text, has more space and a larger total game population to draw upon, and; it reflects the broader shift in management education (1969 to 1997) away from a central pre-occupation with production and production organisations.

\subsubsection{General OM Games}

It was expected that the OM content would be fully integrated into the business games that are not OM specific. By this, we mean that the effect of functional $O M$ decisions would have the same impact as those of other functional areas. On the surface, it would appear that this is the case, with almost half of the data set (109, $49.1 \%$ ) being made up of general/whole organisation games that have substantial OM-related content. One of the earliest such games, the Harvard Business School 
Management Simulation (McKenney 1962, 1967; McKenney and Dill 1966) for example, allows teams to make "[d]ecisions in all the functional areas of business. In the area of manufacturing teams must purchase and warehouse raw materials, schedule production and determine labor utilization" (Graham and Gray 1969, p.210). More recently, a game like Arkea Europe involves players in the manufacture and marketing of a range of related products through a vertically integrated company. Its principle use is to "increase management skills related to different functions of a business [and] their integration [into] a strategic plan" (Elgood 1997, pp.142-3). Similarly, Bizsim (Fripp 1993) is a manufacturing industry game whose primary purpose is to "increase understanding of the interrelationship between different business functions" (Elgood 1997, p.159). However, closer investigation reveals that although issues, such as determining total productive capacity, demand planning, work scheduling etc. have a significant influence upon effective game play the $\mathrm{OM}$ elements have at best, 'order qualifying' effects upon overall performance. Moreover, it can be argued that the fundamental teaching themes and the reported key learning points principally relate to generic issues of time-constrained and sequential decision-making, organisational communication, cross-functional integration, coordination of overall strategy, etc. In other words, when compared with many of the OM-specific exemplars, the structure of these games is much closer to the generic definition introduced earlier in the paper. At the same time, explicit competition between teams and meaningful profitability rules that can be translated into different strategic options (e.g. not worrying too much about production!) may approximate 'real' business motivation but it does not necessarily guarantee that players will learn specific OM lessons. In pedagogical terms therefore, these games are of questionable use for the OM instructor.

\subsubsection{M Specific Games}

Considering the content of OM Specific games, it might reasonably be expected that the content has changed over the time covered by the three datasets, to reflect the changes in the nature of the subject that have occurred over this period. In particular, the move away from considering purely planning and control issues to a strategic view of operations, and from production management to a mix that reflects the increased importance of services. This change has certainly been reflected in the content of OM courses, when one considers the differences in the texts used e.g. Starr (1972) cf. Slack et al (2003), Chase et al, (2003). However, as shown in Table 3 this is not the case. The topics covered by the games are presented in ranked 
order, including an analysis of both the overall and the three individual sets of games in terms of basic subject areas.

\begin{tabular}{|l|l|l|l|l|l|}
\hline & OM CONTENT & A & B & C & TOTAL \\
\hline 1 & Manufacturing Production Control (inc. inventory, EOQ, scheduling, MRP) & 18 & 1 & 12 & $\mathbf{3 1}$ \\
\hline 2 & General Manufacturing and Service Operations & 5 & 7 & 9 & $\mathbf{2 1}$ \\
\hline 3 & Service Quality (inc. complaint and recovery, customer care, etc.) & & 11 & & $\mathbf{1 1}$ \\
\hline 4 & Logistics/Supply Chain Management & 3 & 3 & 4 & $\mathbf{1 0}$ \\
\hline 5 & Capacity/Demand (inc. strategy, forecasting, investment appraisal) & 3 & 5 & & $\mathbf{8}$ \\
\hline 6 & Manufacturing Quality Management (inc. SPC, TQM, Kaizen) & 1 & 6 & & $\mathbf{7}$ \\
\hline 7 & New Product Development (inc concurrent engineering) & 1 & 3 & 2 & $\mathbf{6}$ \\
\hline $8=$ & Purchasing & 2 & 1 & & 3 \\
\hline $8=$ & Just-In-Time (inc. Lean Production) & & 2 & 1 & $\mathbf{3}$ \\
\hline $8=$ & Plant/Product Maintenance and Repair & 3 & & & $\mathbf{3}$ \\
\hline $8=$ & Modelling and Process Re-Design & & & 3 & $\mathbf{3}$ \\
\hline $8=$ & Supervision and Workforce Management (inc. leadership) & 1 & 1 & 1 & $\mathbf{3}$ \\
\hline 13 & Process Technology (inc. FMS and CAD/CAM) & & & 2 & $\mathbf{2}$ \\
\hline $14=$ & Team working & & & 1 & $\mathbf{1}$ \\
\hline $14=$ & International Operations Strategy & 1 & & & $\mathbf{1}$ \\
\hline & TOTAL & $\mathbf{3 8}$ & $\mathbf{4 0}$ & $\mathbf{3 5}$ & $\mathbf{1 1 3}$ \\
\hline
\end{tabular}

Table 3. Summary of OM-Specific Game Content

Firstly, one specific health warning should be attached to the analysis: for instance, although logistics and supply chain related games ranked fourth on the list (10, $8.85 \%$ ), at least 4 of these games are variants on the classic 'beer game' developed to illustrate the Bull Whip effect (e.g. Lee et al. 1997a,b; Holweg and Bicheno 2002).

Notwithstanding these reservations, the first two categories together account for 52 (46.02\%) of the OM-specific games. The largest group (31, $27.43 \%$ of total and ranked 1 for both $\mathrm{A}$ and $\mathrm{C}$ ) of games explore the value and application of different manufacturing planning and control techniques. Correspondingly, most of these games are based around technical production themes, such as the scheduling of machine capacity, inventory control (EOQ, JIT, MRP), maintenance, workforce and work scheduling, etc. Positively, this suggests that the teaching of specific techniques is an important part of OM gaming - perhaps reflecting a recognition that the main challenge of a technique arises from its practical application (in a complex setting etc.). At the same time, whilst planning and control is undoubtedly an enduring core OM subject area, it is unlikely that any modern curriculum would feature more than a single game focused exclusively upon the issue. Pragmatically, the popularity of these games is equally likely to reflect the advantages of adapting a quantitative and rule-based subject for gaming purposes and the relative ease with which rules can be structured for such a game, compared with something more qualitative, such as service quality. Moreover, contrary to expectations, the pre-eminence of 
manufacturing planning and control has not lessened over time as much as would be expected - certainly between $\mathrm{A}$ and $\mathrm{C}$. However, this may be mitigated by observing the other classifications that could be viewed as manufacturing planning and control - specifically categories 4,5 and 8 (logistics/supply chain, capacity/demand, JIT). When this is taken into account, the figures for the wider view of MPC, are A: 24, $\mathrm{B}: 11$, and $\mathrm{C}: 17$ games. Thus there is an apparent trend here, but it certainly does not reflect the changed emphasis in the teaching support literature. The lack of any recent games concerned with International Operations Strategy, for instance, is also of concern.

Lastly, the second most common type of game $(21,18.6 \%)$ can be classified as illustrative of general (predominantly manufacturing) OM practice. These games implicitly address issues of operations strategy (e.g. co-ordinating multiple improvement options) but successful game play (explicit in umpire instructions and rules) is always predicated upon an analysis of whatever factors constitute the given market and competitive context. In other words, the key strategic lessons of these games relate to an 'outside $\rightarrow$ in' model of strategic fit whereby the strategic role of operations is limited to aligning itself with other functions and the external marketplace. This is undoubtedly suitable for introducing students to the basic concepts of OM, but less useful where for instance experienced practitioners are seeking to create genuine class-leading strategies for organisation.

Having considered the relationship between the games market and $\mathrm{OM}$ teaching themes, the following discussion highlights a meta-observation about the degree to which $\mathrm{OM}$ games reflect $\mathrm{OM}$ research priorities. The expectation for this data is not as for the teaching themes - we would not necessarily expect a close correlation between the gaming themes and research themes per se. However, it is interesting to reflect on any potential links. As a simple metric, Table 4 compares the count of game content with a similar analysis of published OM research (Pannirselvam et al. 1999): 15 different research categories ${ }^{5}$, in order of journal publication frequency, are identified. Acknowledging the limited validity of any conclusions, it remains interesting to attempt an approximate matching analysis between the gaming rank and research rank for each category.

\footnotetext{
${ }^{5}$ Project management was an additional category not considered in the game classification.
} 


\begin{tabular}{|l|l|l|}
\hline GAMING THEMES & RESEARCH THEMES & PAIRING \\
\hline 1. Manufacturing Production Control (inc. inventory, EOQ, scheduling, MRP) & 1. Scheduling \& Inventory & $1: 1$ \\
\hline 2. Strategic Management of Manufacturing/Service Businesses & 2. Process Design & $2: 3$ \\
\hline 3. Service Quality (inc. complaint and recovery, customer care, etc.) & 3. Strategy & $3: 9$ \\
\hline 4. Logistics/Supply Chain Management & 4. Quality & $4: 5$ \\
\hline 5. Capacity/Demand (inc. strategy, forecasting, investment appraisal) & 5. Logistics, Distribution & $5: 10,13,14$ \\
\hline 6. Manufacturing Quality Management (inc. SPC, TQM, Kaizen) & 6. Facility Layout & $6: 4$ \\
\hline 7. New Product Development (inc concurrent engineering) & 7. Maintenance & \\
\hline 8=. Purchasing & 8. Purchasing & $8: 8$ \\
\hline 8=. Just-In-Time (inc. Lean Production) & 9. Services & \\
\hline 8=. Plant/Product Maintenance and Repair & 10. Capacity Planning & $8: 7$ \\
\hline 8=. Modelling and Process Re-Design & 11. Facility Location & $8: 2$ \\
\hline 8=. Supervision and Workforce Management (inc. leadership) & 12. Work Measurement & $8: 12$ \\
\hline 13. Process Technology (inc. FMS and CAD/CAM) & 13. Forecasting & \\
\hline 14=. Team working & 14. Aggregate Planning & \\
\hline 14=. International Operations Strategy & 15. Quality of Working Life & \\
\hline
\end{tabular}

Table 4. Comparing Rankings of Gaming and Research Content

A simple 'eyeball' inspection of the paired rankings suggests that while there is a reasonable degree of overall correlation between established research and gaming priorities there are also a number of specific, apparently significant, deviations between the priorities. Some probably reflect the limitations of the data set and the categorisations employed (e.g. many of the general OM games include substantial process re-design elements) but others may be worth highlighting. For instance, Service Quality games ranked third (11, 9.73\%) on the gaming list, whereas services rank 9 on the research list. Although there are still too few service games (e.g. the service quality games are drawn exclusively from set $B$, there are only 14 service games in the total set and none in set $\mathrm{C}$ ), OM gaming appears to better reflect shifts in management priorities, practice and education than OM research. In other words, just as the paucity of service-specific games from the older (and predominantly UScentred) set $A$ is understandable, given the predominance of manufacturing industry in business education of that era, an over-emphasis on manufacturing practice is increasingly inappropriate and imbalanced.

With respect to OM education, there are clearly subject areas where new games need to be developed. For instance, whilst the 'outside $\rightarrow$ in' model of strategic fit is an entirely legitimate and well-established strategic model, it is surprising to find that there are no OM games exploring the conceptually equivalent 'inside $\rightarrow$ out' model of 
fit (Hayes 1985). A complementary logic has triggered significant operations strategy research (Hayes, Wheelwright and Clark 1988, Hayes and Pisano 1996, Bartezzaghi 1999, Gagnon 1999, Lewis 2000, 2003). Equally, there are also potential examples where OM game playing could help address a research agenda. Some experimental game-based OM research does exist, for instance in the various forms of learning/forgetting curve study (Yelle 1979; Globerson, Levin and Shtub 1987; Bailey 1989; Arzi and Shtub 1997) but the method is not as well established as it is in other disciplines like social psychology (Brief et al. 1995) and economics (Tversky and Kahneman 1974).

\subsection{The Gaming Process}

In addition to categorising the games according to the intended teaching outcome, each game was further analysed against a number of process dimensions specifically to see the form of the game (duration and number of players), the level of complexity, the incorporation of physical processes the role of IT and whether the games were competitive. Table 4 summarises the results.

\begin{tabular}{|c|c|c|c|c|c|c|c|c|c|c|c|c|c|c|}
\hline & \multicolumn{7}{|c|}{ OM SPECIFIC } & \multicolumn{7}{|c|}{ OM RELATED } \\
\hline & $\begin{array}{c}T \\
\text { days }\end{array}$ & $\begin{array}{l}P L . \\
\text { min }\end{array}$ & $\begin{array}{l}\text { PL. } \\
\max \end{array}$ & $\begin{array}{c}\text { comp } \\
\text { lex }\end{array}$ & $\begin{array}{c}\text { Physi } \\
\text { cal }\end{array}$ & IT & $\begin{array}{l}\text { comp } \\
\text { etit. }\end{array}$ & $\begin{array}{c}T \\
\text { days }\end{array}$ & $\begin{array}{l}P L . \\
\text { min }\end{array}$ & $\begin{array}{l}\text { PL. } \\
\max \end{array}$ & $\begin{array}{c}\text { comp } \\
\text { lex }\end{array}$ & $\begin{array}{c}\text { physi } \\
\text { cal }\end{array}$ & IT & $\begin{array}{l}\text { comp } \\
\text { etit. }\end{array}$ \\
\hline \multicolumn{15}{|l|}{$A+B+C$} \\
\hline MEAN & 3.5 & 12 & 26 & & & & & 1.5 & 6 & 36 & & & & \\
\hline MODE & 1 & 1 & 24 & & & & & 1 & 12 & 36 & & & & \\
\hline \multirow{2}{*}{ RANGE } & 0.05 & 1 & 1 & & & & & 0.1 & 1 & 2 & & & & \\
\hline & 10 & 30 & 175 & & & & & 5 & 32 & 300 & & & & \\
\hline ST.DEV & 1.58 & 5.36 & 24.68 & & & & & 1.10 & 6.47 & 52.08 & & & & \\
\hline$\%$ TOTAL & & & & 70.80 & 32.74 & 57.52 & 30.97 & & & & 97.25 & 7.34 & 80.74 & 60.55 \\
\hline \multicolumn{15}{|l|}{$A$} \\
\hline MEAN & 1 & 4.5 & 55.13 & & & & & 0.96 & 11.31 & 47.64 & & & & \\
\hline MODE & 1 & 1 & 50 & & & & & 1 & 12 & 30 & & & & \\
\hline \multirow{2}{*}{ RANGE } & 0.2 & 1 & 10 & & & & & 0.25 & 1 & 4 & & & & \\
\hline & 1.25 & 15 & 175 & & & & & 3 & 32 & 160 & & & & \\
\hline ST.DEV & 0.37 & 4.34 & 54.09 & & & & & 0.74 & 7.79 & 39.34 & & & & \\
\hline \% TOTAL & & & & 60.53 & 5.26 & 57.89 & 71.05 & & & & 95.65 & 2.17 & 69.57 & 97.83 \\
\hline \multicolumn{15}{|l|}{$B$} \\
\hline MEAN & 1.65 & 16 & 25.79 & & & & & 1.55 & 7.36 & 52.68 & & & & \\
\hline MODE & 0.1 & 8 & 24 & & & & & 2 & 12 & 36 & & & & \\
\hline \multirow{2}{*}{ RANGE } & 0.05 & 1 & 6 & & & & & 0.1 & 1 & 2 & & & & \\
\hline & 5 & 20 & 48 & & & & & 5 & 27 & 300 & & & & \\
\hline ST.DEV & 1.05 & 4.47 & 13.49 & & & & & 1.15 & 5.03 & 57.09 & & & & \\
\hline$\%$ TOTAL & & & & 60 & 47.5 & 50 & 20 & & & & 98.41 & 11.11 & 88.88 & 33.33 \\
\hline \multicolumn{15}{|l|}{$C$} \\
\hline MEAN & 1.79 & 8.05 & 16.29 & & & & & & & & & & & \\
\hline MODE & 1 & 1 & 1 & & & & & & & & & & & \\
\hline RANGE & 0.25 & 1 & 1 & & & & & & & & & & & \\
\hline & 10 & 30 & 36 & & & & & & & & & & & \\
\hline ST.DEV & 2.08 & 6.50 & 12.13 & & & & & & & & & & & \\
\hline \% TOTAL & & & & 94.28 & 45.71 & 65.71 & 5.71 & & & & & & & \\
\hline
\end{tabular}

Table 4. Summary of Game Process Details 
The specific parameters measured were as follows: mean game duration in days (8 hours = 1 day); minimum and maximum number of players ${ }^{6}$; classification of the game as either simple (defined as comprising fewer than five variables for players to manipulate) or complex; incorporation of 'physical' (e.g. cutting of paper, moving counters on a board) processes; requirement for IT support (including for scoring an otherwise manual game); competitive or non-competitive (i.e. there may be formal evaluation of game play but does a winner emerge) gaming rules. Discussion will be collated under four themes detailing game structure and infrastructure, game complexity, role of IT, and the role of competition.

\subsubsection{Game Structure and Infrastructure}

Some games in the set only required 20 minutes of player participation but most - in both the OM-specific (mean: 3.5 days; mode: 1, max: 10) and OM-related (mean: 1.5 days; mode: 1 , max: 5 ) categories - required extended periods of time to play. The level of commitment necessary to undertake games that require days of player time probably reflects their origins and application in formal educational settings where the umpire (e.g. a professor) can mandate participation, indeed several of the longest duration games are intended to be used over entire semesters. Across the different sets, $B$ has both the shortest specific games ( 0.05 day) and the lowest average duration (mean: 1.6; mode: 0.1 , max: 5): this may be explained by the inclusion of more private-sector training and development consultancy-type games. Complexity also relates directly to duration, with the 34 'simple' games having a mean length of just 0.34 days (mode: 0.5$)^{7}$

Although for both the OM-specific (mean min: 12, mean max: 26) and OM-related (mean min: 6, mean max: 36) categories the mean range of players suggests teambased games, the modal player numbers reveal a potentially different picture. For the total OM-specific set, the modal minimum is 1 player and set $C$ has a modal minimum and maximum of 1 player. It can be argued that this emphasis on solitary game play can again be explained by the necessity of teaching specific tools and techniques but unfortunately such a controlled teaching requirement means that

\footnotetext{
6 Where the game is team-based a range is given for both minimum and maximum

$7 \mathrm{It}$ is noted that there are often many modes for the execution of a game by an instructor (e.g. number of rounds played, time given for reflection and umpire intervention), and so the figures given for individual games are not in any sense exact but just give a notional duration for the purposes of comparison.
} 
these games lack much of the group and organisational behaviour 'realism' and 'fun' associated with whole business games.

\subsubsection{Game Complexity}

The vast majority of both the OM-specific (70.8\%) and OM-related games are classified as complex. This seems to reflect a belief that such games are better reflections of operational 'reality' and therefore more valuable pedagogical devices: in particular (97.25\% of OM-related games are complex) where the primary intent is to provide a vehicle for exploring whole system issues. It is noted that game complexity includes a relatively involved umpire/facilitator role. Indeed, for a number of the games, multiple umpires are prescribed because of the need to retain control of the process and the outcomes of the game. The New Orsiam International Game developed by Professor R.H. Muller of the University of Ghent for instance, involves between 12 and 36 people, simulating 4 to 6 companies playing against each other and a "fully automated multi criteria evaluation procedure ... applied to select the winner" (IFIP). A key limitation of the game is described thus: "intense involvement and dedication of game co-ordinators is necessary". Conversely, the level of control exerted by the umpire in many of the complex OM-related games is deliberately minimal - despite the game being played to a complex set of rules. The purpose of these game appears to be to allow players to 'figure it out' for themselves. The figures are distinctly different between the OM specific and the OM related sets and there does appear to be a trend towards more complex games in the OM specific set.

This strong bias towards complex games requiring extensive umpire support/intervention seems to reflect the dominant logic of current OM game design. The true value, both conceptually and practically, of such complexity has to be questioned however. It is important to establish if this tendency is akin to that identified within OM research of seeking to develop "more complex models [that] we presume are more realistic, since they take into account more variables" but which some authors view as having taken the discipline away from "dealing with the broader managerial implications of decisions in production systems" (Buffa 1982). There seems to be an implicit assumption, but no clear supporting evidence, that experienced managers accept game formats that replicate more closely their actual work environment - indeed the converse could actually be true. Similarly, it is not clear whether there is a push or a pull relationship between the ubiquitous IT sophistication and gaming complexity. At a recent conference (EurOMA/POMS 2003) for instance, the author attended a session where UK and US participants discussed 
the use of mass market computer games - such as Theme Park and Theme Hospital - in teaching. In particular, the discussion questioned the usefulness of highly complex games, and demonstrated instructors' preferences for short, easy-to-run scenarios that could easily be integrated, say into a 2 or 3-hour lecture slot.

\subsubsection{Incorporation of physical processes}

Experience with $\mathrm{OM}$ games suggests that wherever possible, some physical process helps with establishing a connection with the gaming environment for players. It was surprising therefore, to note that of the OM specific games there was little use of physical processes in dataset $A$, and still less that half of the games involving physical processes in the more recent datasets. This is at odds with the finding that much of the gaming content was concerned with manufacturing and physical product issues (including logistics and inventory management).

In the OM related games, the levels of physical processes were even less, with only $11.11 \%$ of dataset $B$ including physical processes. This is consistent with the earlier finding noted as 'don't worry about production' in the OM related games. Whilst it is clearly easier for an instructor if physical issues of a game can be discounted (one less thing to organise) such artefacts were an intrinsic part of our earlier transformation model. It is clear that the typical OM game does not involve the transformation of such artefacts; rather information is transformed in the majority of games.

\subsubsection{Role of IT in games}

The first point of note is how the earliest data set from 1969 contained a substantial proportion of games that required IT support (57.89\% of OM specific, 69.57 of OM related). Clearly, this will have changed in nature over the three surveys, but here is evidence of an appetite in the providers to claim intellectual property through the development of proprietary IT elements of the games. Overall, the majority of all OM games require some degree of IT support (57.72\% of OM specific, $80.74 \%$ of OM related). More specifically, many of the recent games ( $B$ and $C$ ) were entirely PCbased or needed a computer simulation to provide the gaming context and evaluate performance (i.e. interpret rule-based outcomes). For example, the FMS Design Game (IFIP) requires a PC Windows environment, Excel spreadsheet, FORTRAN queue theory modules and the Witness simulation package. This emphasis on using infrastructure to deal with complexity and increase gaming realism appears to be 
extremely significant for OM. Arguably, this trend reaches its natural conclusion in facilities such as the electronics industry training factory at the University of Oulu, Finland (Haapasolo and Hyvönen 2001, p.265). This provides a networked learning environment and a complete facsimile of a factory layout (complete with integrated manufacturing technologies on different floors) to support its 'fast-cycle' production simulation. However, consistent with the transformation model proposed in Fig. 1, there is only so much of teaching games that can be automated, and indeed, it is notable that there are still a significant number of games in samples $B$ and $C$ that are not IT-centric nor require IT support. This may be consistent with the level of complexity and duration - shorter, less complex games requiring less processing of data.

\subsubsection{Role of Competition}

Competition in the context of OM games is considered to arise where there is a benchmark for players to measure their performance against. This benchmark may be generated dynamically by other players in the same game, or by some notion of optimality provided by the gaming system. The authors experience would lead them to a hypothesis that competition in either of these forms is a desirable feature of games and that this would be a consistent feature of OM specific games. Where there is such an obvious immediate reward mechanism (beyond possible course credits for players) we have observed enormous levels of commitment to the spirit as well as the content of games, that has been most enlightening for all involved. The positive aspects of competition have introduced more fundamental questions of realism than any amount of additional rules could have done. There are however three adverse effects of competition that we have noted. The first is the 'we quit' team - where a group falls behind its competitors, and decides that it is not worth continuing with a high level of effort to try to catch up. The second is where a team 'wins' or performs at a high level in comparison with the other teams, but this then masks the insights that they might have gained, because they lose the ability to be able to conceive that they could have made changes that would have allowed them to perform even better. Thirdly, despite some limited discussion of player 'appropriateness', the descriptions included in the data set suggest that there has been insufficient reflection upon the impact of key player variables (e.g. player work and gaming experience, educational and managerial level). This could be particularly significant where, for instance, the players are ambitious employees or senior managers and already apprehensive about being peer-evaluated (Weick 1977, 
p.124). Add in a competitive game process, especially one linked with deliberately contrived situational confusion and this player/game type combination could make it very difficult for them to (at least initially) engage with the game play.

Using competitive game playing may not be the most appropriate for all students, but the exceptions noted have been rare. We argue that on balance it is desirable that there is an explicit motivation central to the logic of the game, and competition is one means to generate this. However, the datasets show that only $30.97 \%$ of the OMspecific and $60.55 \%$ of the OM-related games involve the explicit use of competitive dynamics. Moreover, there is a clear change in the incidence of competition in the datasets - declining from $71.05 \%$ in set $A$, to only $5.71 \%$ in set $\mathrm{C}$. The reasoning behind this might include the nature of the gaming - where current product offerings give the opportunity for a different type of play. We constructed this as experimentation, rather than competition earlier in the paper. For instance, one of set A games is the Production Scheduling Management Game. This is described as a "non-competitive production control game". It requires players to "schedule jobs on three machines in a production department .... [players] must decide which jobs to accept and the exact production schedule." The sole purpose of the game is to illustrate the benefits of "systematic procedures" (Graham and Gray 1969, p. 346). We would classify this game as giving the possibility for active experimentation, rather than explicit competition.

\section{Concluding Comments}

The development of games has been the focus of practitioner and academic interest for more than fifty years and this review has attempted to summarise some of the breadth and depth of gaming practice in OM education. This was prompted by the authors' own extensive and very positive experience with using games as a core part of OM courses. Two areas of interest were identified for this paper. The first was to consider the content of OM games. The second was to consider the process. The whole discussion was framed by a transformation model of gaming, which allowed the process of playing the game to be analysed.

The market offering for games was based on a database of 222 games collated from three secondary sources. The games were divided into those that were OM specific and OM relevant. The OM specific games were further analysed to determine their nature and usefulness in teaching OM. The conclusion was drawn that although OM issues were present in many of the OM relevant games, the content was such that 
the role of $\mathrm{OM}$ was not given sufficient prominence to be classified as anything more than introductory. This was contrary to expectations - we had expected the gaming market to have progressed in a manner consistent with the development of OM in both theory and practice. Similarly in the market for OM specific games, it was noted that there is a preponderance of quantitative manufacturing-oriented games, against a trend to more qualitative service-based subjects in OM content. When compared with the concerns of OM publications, the levels of occurrence of particular topics had some similarity, yet the preponderance of an 'outside-in' view of strategy was noted. However, it was noted that the games were a better representation of the current industrial context than the incidence of published research.

In further examining the nature of the games, it became clear that there was a preponderance of highly complex games, with a significant role for the umpire. In terms of educational utility, this was questioned, as the abstracted reality was being made complex as a surrogate for being close to reality. In addition, it does need to be considered if these are indeed what instructors need or whether the development of less complex, short scenarios would be pedagogically beneficial.

In considering the role of IT in the games, there is a long tradition of IT being used in the support of games. We note that this support has changed over time, with the games from the early data set using IT as number-processing support, whereas today such support would be fairly trivial, compared to the dynamic mulit-media possibilities that exist. Despite concerns that all games would require IT interaction, there is still a significant number of games that require little or no IT input.

The numbers of competitive games on offer to the OM educator has decreased significantly over the past 35 years. This is not completely explained by the data nor by the experience of running competitive games by the authors. This does inform the debate on the definition of game (e.g. McKenny, 1967) and shows that 'play as experimentation' is now the predominant mode of gaming.

\section{Further Work}

The analytical findings and conclusions presented in this paper also highlight many areas that warrant further work. It is proposed that the following two areas merit particular attention. 
1. Many of the themes highlighted in this critical review clearly relate to design decisions but the data set of 'finished' games does not permit direct analysis of the new game design (NGD) process. Therefore, a future study could usefully analyse a smaller set of games in more detail, seek to identify common components (c.f. product platforms, design modularity) and develop some kind of design typology, for instance. Moreover, those authors who have discussed the NGD process (Gibbs 1974, Hitchcock 1988, Fripp 1993) have largely positioned it as a rational knowledge generation approach akin to the conceptualisation, modelling, model solving and, implementation research cycle. Given the state of knowledge about new product and service development (e.g. Brown and Eisenhardt 1995) however, such a simplistic model needs refining to include potential trade-offs: for example, to 'teach' specific content, how a game needs to be controlled so that 'events of interest' actually occur yet this may run counter to fair game playing. The challenges posed by having a highly diverse group of players (e.g. levels of experience), the role of physical artefacts and the issue of competition and strategy development (outside in vs. inside out) in OM gaming clearly need to be better understood.

2. Close examination of the data set reveals how challenging it is to describe a dynamic social phenomenon like a game. There is clearly a need to consider alternative game reporting and sharing mechanisms between instructors (e.g. a game clearing house, as exists for case material). This needs to be supported by some form of empirical investigation into actual usage of the games, triangulating umpire, player and third party observer feedback. This quasiresearch approach, taking advantage of modern AV technology (a digital video collection of games being played) would offer a much richer insight into the advantages and disadvantages of different types of game inputs, processes and outcomes. This paper has provided a foundation for such work.

\section{References}

1. Allen, T.B. (1987). War Games: The Secret World of the Creators, Players and Policy Makers Rehearsing World War III Today, Mc-Graw Hill, NY.

2. Ammar, S. and R. Wright (1999). "Experiential Learning activities in Operations Management", International Transactions in Operational Research, Vol. 6, pp. 183-197.

3. Arzi, Y. and A. Shtub (1997). "Learning and Forgetting in mental and mechanical tasks: a comparative study", IIE Transactions, September.

4. Babb, E.M. and L.M. Eisengruber (eds.) (1966). Management Games for Teaching and Research, Educational Methods Inc., Chicago, III. 
5. Bailey, C.D. (1989). "Forgetting and the Learning Curve: a laboratory study", Management Science, Vol. 35, No. 3, pp. 346-352.

6. Bartezzaghi, E. (1999). "The evolution of production models: is a new paradigm emerging?", International Journal of Production and Operations Management, Vol. 19, No. 2, pp. 229-250.

7. Bowen, K.C. (1978). Research Games: an approach to the study of decision processes, ORASA text No. 3, Taylor and Francis, London. ISBN 0850661692

8. Brief, A.P., Butcher, A.H. and Robertson L. (1995). "Cookies, disposition and job attitudes: The effect of positive mood inducing events and negative affectivity on job satisfaction in a field experiment", Organizational Behavior and Human Decision Processes, Vol. 65, pp. 55-62.

9. Brown, S.L. and Eisenhardt, K.M. (1995). "Product Development: Past Research, Present Findings and Future Directions", Academy of Management Review, 20(2), pp. 343-378.

10. Buffa, E.S. (1982). "Research in Operations Management", Journal of Operations Management, 1(1), pp. 1-7.

11. Carson, J.R. (1967). "Business Games: A technique for teaching decision-making", Management Accounting, October, p.31.

12. Chase, R., Jacobs, F.R. and Aquilano, N. (2003), Operations Management for Competitive Advantage (10 th edition), McGraw Hill, New York.

13. Deming, W.E. (1986). Out of the Crisis, MIT Press, Boston, MA

14. Elgood, C. (1997). Handbook of Management Games and Simulation (6th edition), Gower Publishing, Aldershot

15. Emerson, H.P. and D.C.E. Naehring (1988). The Origins of Industrial Engineering, Institute of Industrial Engineers, Norcross, G.A.

16. Forrester, J.W. (1961). Industrial Dynamics, MIT Press, Cambridge, MA.

17. Fripp, J. (1993). Learning through Simulations: A Guide to the Design and Use of Simulations in Business and Education, McGraw-Hill Training Series, London.

18. Gagnon, S. (1999). "Resource-based competition and the new operations strategy", International Journal of Production and Operations Management, Vol. 19, No. 2, pp. 125-138.

19. Gibbs, G.I. (1974). Handbook of Games and Simulations, Clowes and Son, London.

20. Globerson, S., N. Levin, and A. Shtub (1989). "The impact of breaks on forgetting when performing a repetitive task", IIE Transactions, Vol. 21, No. 4, pp. 376-381.

21. Gordon, R.A. and J.E. Howell (1959). Higher Education for Business, Columbia University Press, NY.

22. Graham, R.G. and C.F. Gray (1969). Business Games Handbook, American Management Association.

23. Greenlaw, P.S., L.W. Herron, and R.H. Rawdon (1962). Business Simulation in Industrial and University Education, Prentice-Hall, NY. 
24. Haapasalo, H. and J. Hyvönen (2001). "Simulating business and operations management - a learning environment for the electronics industry", International Journal of Production Economics, Vol. 73, pp. 261-272.

25. Hayes, R.H. (1985), "Strategic Planning - Forward in Reverse?" Harvard Business Review, JulyAugust, pp. 56-66.

26. Hayes, R.H. and Pisano, G. (1996), "Manufacturing Strategy: At the Intersection of Two Paradigm Shifts", Production and Operations Management, Vol 5, No.1, Spring, pp 25-41.

27. Hayes, R.H., Wheelwright, S.C. and Clark, K.B. (1988). Dynamic Manufacturing: Creating the Learning Organization, Free Press, New York.

28. Hitchcock, D.E. (1988). "Building Instructional Games", Training, 25(3), p. 33-39.

29. Holweg, M. and Bicheno, J. (2002). "Supply Chain Simulation - a tool for education, enhancement and endeavour", International Journal of Production Economics, 78, pp. 163-175.

30. Huizinga, J. (1971). Homo Ludens: A study of the play-element in culture, Beacon Press, London.

31. Jackson, P. (1996). "The Cups Game”, NSF Product Realization Consortium Module Description, Cornell University, Ithica, NY.

32. Kolb, D.A. (1985), Experiential Learning, Prentice Hall, Englewood Cliffs, NJ.

33. Klasson, C.R. (1964). "Business Gaming: A Progress Report", Academy of Management Journal, Vol. 7, No. 3, September, pp. 175-188.

34. Lee, H.L., V. Padmanabhan, and S. Whang (1997a). "The bullwhip effect in supply chains," Sloan Management Review, Spring, pp. 93-102.

35. Lee, H.L., V. Padmanabhan, and S. Whang (1997b). "Information Distortion in a Supply Chains," Management Science, 43, pp. 546-558-102.

36. Lewis, M.A. (2000). "Lean Production and Sustainable Competitive Advantage", International Journal of Production and Operations Management, Vol. 20, No. 8, pp. 959-978

37. Lewis, M.A., (2003). "Cause, Consequence and Control: towards a practical and conceptual model of operational risk". Journal of Operations Management, 21, pp. 205-224.

38. McKenney, J.L. (1962). "An Evaluation of Business Games as a Learning Experience", Journal of Business, Vol. 35, pp. 278-286.

39. McKenney, J.L. (1967). Simulation Gaming for Management Development, Harvard Business School, Division of Research

40. McKenney, J.L. and W.R. Dill (1962). "Influences on Learning in Simulation Games", American Behavioural Scientist, Vol. 10, No. 2, October, pp. 28-32.

41. Pannirselvam, G.P., Ferguson, L.A., Ash, R.C., and Siferd, S.P. (1999). "Operations Management Research: An update for the 1990's", Journal of Operations Management, Vol. 18, pp. 95-112.

42. Riis, J.O. and Mikkelsen, H. (eds.) (1995). Simulation Games and Learning in Production Management, Chapman and Hall, London. 
43. Robinson, A.G. and M.M. Robinson (1994). "On the Tabletop Improvement Experiments of Japan", Production and Operations Management, 3(3), Summer, pp. 201-216.

44. Schrage, M. (1999), Serious Play, HBS Press, Boston MA.

45. Senge, P. (1990). The Fifth Discipline: The Art and Practice of the Learning Organisation, Doubleday, NY.

46. Shubik, M. (1960). "Games, Decisions and Industrial Organization”, Management Science, Vol. 6. No. 4, July, pp. 40-54.

47. Shubik, M. (1972). "On the Scope of Gaming", Management Science, Vol. 18. No. 5, part 2.

48. Shubik, M. (1975a). The Uses and Methods of Gaming, Elsevier, NY.

49. Shubik, M. (1975b). Games for Society, Business and War: Towards a Theory of Gaming, Elsevier, NY.

50. Slack, N., Chambers, S. and Johnston, R. (2003), Operations Management (4th edition), FT Prentice Hall, Harlow.

51. Smeds, R. (1997). "Organizational Learning and Innovation through Tailored Simulation Games:

Two Process Re-Engineering Case Studies", Knowledge and Process Management, Vol. 4, No. 1, pp. 22-33.

52. Smeds, R. and Riis (1998)

53. Starr, K. (1972), Production Management, $2^{\text {nd }}$ edition, Prentice Hall, Englewood Cliffs, NJ.

54. Tversky, A. and Kahneman, D. (1974). "Judgement under uncertainty: heuristics and biases", Science, 185, pp. 1124-1131.

55. Weick, K.E. (1977). "Conceptual Notes: Laboratory Experimentation with Organizations: A Reappraisal", Academy of Management Review, January, pp. 123-1328.

56. Weick, K. E. (1995), Sensemaking in Organisations, Thousand Oaks CA, Sage.

57. Weir, D.T.H. (1997). "Foreword" in C. Elgood, Handbook of Management Games and Simulations, Gower, Aldershot, U.K., pp. ix-xi.

58. Yelle, L.E. (1979). "The Learning Curve: historical review and comprehensive survey", Decision Sciences, 10. pp. 302-328. 